\title{
AIR POLLUTION ALERT SYSTEM USING IOT WITH GPRS
}

Kalpana Murugan

Department of Electronics and Communication Engineering, Kalasalingam Academy of Research and Education, Krishnankoil, Virudhunagar (Dt), (India). E-mail:drmkalpanaece@gmail.com ORCID: https://orcid.org/0000-0002-5121-0468

S. Murugeswari

Department of Electronics and Communication Engineering, Kalasalingam Academy of Research and Education, Krishnankoil, Virudhunagar (Dt), (India).

E-mail: sudha.murugeswari@gmail.com ORCID: https://orcid.org/0000-0002-5240-4360

Vaishnavi Parlapalli

Department of Electronics and Communication Engineering, Kalasalingam Academy of Research and Education, Krishnankoil, Virudhunagar (Dt), (India).

E-mail: vaishnavi31198@gmail.com ORCID: https://orcid.org/0000-0003-1012-1618

\section{Gherukuri Mohana Teja}

Department of Electronics and Communication Engineering, Kalasalingam Academy of Research and Education, Krishnankoil, Virudhunagar (Dt), (India). E-mail: cherukuriteja77@gmail.com ORCID: https://orcid.org/0000-0001-6541-6179

Karasala Triveni

Department of Electronics and Communication Engineering, Kalasalingam Academy of Research and Education,Krishnankoil, Virudhunagar (Dt), (India).

E-mail: triveni1898@gmail.com ORCID: https://orcid.org/0000-0001-5015-7063

\section{Citación sugerida:}

Murugan, K., Murugeswari, S., Parlapalli, V., Teja, C. M., y Triveni, K. (2021). Air pollution alert system using IoT with GPRS. 3C Tecnología. Glosas de innovación aplicadas a la pyme, Edición Especial, (noviembre, 2021), 99-111. https://doi.org/10.17993/3ctecno.2021.specialissue8.99-111 


\section{ABSTRACT}

The air pollution is considered as the major problem which is caused due to the increase of the vehicles. To reduce the air pollution, many countries has explained different technologies like Zigbee based monitoring system which is used to measure the quality of an air. In this project a Wireless Inspection and Notification System (WINS) is proposed through the concept of Internet of Things (IoT). By implementing the system, it is possible to identify the harmful gases that present in the environment. In this WINS system, it uses GPRS based technology as a low cost and smart wireless communication method is adopted to collect and transmit the information about the harmful gases. The collected information will be stored for future purposes. To detect the environment pollution, proposed system uses different gas sensors i.e., CO sensor, MQ135 gas sensor and LM35 temperature sensor which is used to detect the pollution that present in the environment.

\section{KEYWORDS}

Air pollution, WINS, IoT, Wi-Fi module, CO sensor, MQ135 sensor, LM35 temperature sensor. 


\section{INTRODUCTION}

IoT is a system which is related to all types of devices such as electronic, mechanical, some objects and all other living organisms. It helps in transferring data without any human support. It is generally used where network connectivity comes into the picture. It allows devices to exchange data between any two objects with minimum human interaction. With the help of IoT based technology scientists have developed new security challenges and ensuring security to IoT based products is given as major priority. Also, IoT induces faith within users so they believe that the IoT based systems do not have any weakness (vulnerability). In case if these products are secured properly there is a chance of potential breach.

GPRS (General Packet Radio Service) is a TTL based module. The type of GPRS used is SIM900. The frequency range available in India for GPRS module is between 900- 1900 Mhz. In other countries like U.S it can be used below 900 i.e., 850 Mhz. The proposed system works with a power supply of $5 \mathrm{v}$. Also, this system provided with an inbuilt rectifier that reduces the input voltage of any value to its required number of volts.

Air pollution occurs when the large amount of biological and gaseous substances is exposed to atmosphere. This results the emergence of several new diseases and sometimes it leads to death of living organisms. Not only living beings but also it causes damage to food crops and may even damage environment. Main reasons behind all these activities are excessive use of gas emitting machinery. This problem is mainly observed in metropolitan cities like Chennai, Bangalore etc., this problem even leads to change in climate condition in an untimely manner. The main remedy to eradicate air pollution is by utilizing natural power supplies like solar energy, wind energy and tidal energy instead of these harmful machineries.

In Now-a-days air pollution is the major problem of every country. Due to this air pollution many people are facing different health issues. The rate of health issues has been growing faster in many areas which contain developing industrialization. It also may be due to the increase of number of vehicles which releases harmful gases. In this system the quality of air will be monitored, and it provides the output in threshold values. The proposed system uses three different sensors such as MQ135, MQ7. LM35 sensor is added in this system to 
show the amount of temperature and humidity. These sensors are used to identify different types of gases like $\mathrm{CO} 2, \mathrm{CO}$, and Benzene. When these gases are detected by the sensors, the gases values are measured, and the threshold values of the gases are displayed on the LCD. When the threshold value is beyond the particular level, it provides buzzing sound by the buzzer that present in the system. This proposed system can be installed anywhere but mostly in industries and houses, where gases are mostly to be found.

In this IoT project it uses Arduino UNO, CO sensor, MQ135 gas sensor and LM35 temperature sensor, which is used to monitor the pollution level. This system uses GPRS module to monitor the air pollution from any place using PG or mobile. In SECTION-II, related literature survey was discussed. In SECTION-III, has been discussed along with its proposed method. In SECTION-IV, the results have analyzed and discussed. Finally, this paper is concluded with a Conclusion in the SECTION-V.

\section{RELATED WORK}

Mansour et al. (2014) explains about a set of gas sensors that are developed on stacks and infrastructure of a ZigBee and central server will support both short-term real time incident management and a long-term strategic management. It is a low data rate and low power wireless communication technology. Low-cost air-quality monitoring nodes consist of gas sensors with Wi-Fi module (Parmar, Lakhani, \& Chattopadhyay, 2017; Xiaojun, Xianpeng, \& Peng, 2015). It evaluates concentration of gases like CO, CO2, SO2 using sensors. The monitoring system has highly complex equipment technology and unstable operation. A wireless multi-gas sensing system is capable to identify the concentration of harmful elements like $\mathrm{CO}, \mathrm{CO} 2$ and $\mathrm{CH} 2 \mathrm{O}$. A mobile app is developed to show data related to the concentration of gases when it is too high. The hardware sharing technique is used to reduce the hardware cost (Huang et al., 2018).

Papers of Phala, Kumar, and Hancke (2016) and Kumar and Jasuja (2017), uses set of sensors to take the measurements of air present in the environment. The wireless network transmits the information to the base station. Gas concentration values are plotted on the Graphical User Interface (GUI). Low-cost air pollution sensors used to monitor air pollution at spatio temporal resolution. Sensor calibration must be effective to improve 
the data quality. Data quality of sensors is used to maintain the reliability (Maag, Zhou, \& Thiele, 2018).

Recurrent air quality predictor is used to monitor the air quality. It provides one-hour prediction model which is used to monitor the current values of air pollution and to predict the air quality (Gu, Qiao, \& Lin, 2018).

Papers of Cataliotti et al. (2014) and Devahema et al. (2018) contain different kinds of data sources received from open IoT platform and gives access to users. This work majorly deals with the different types of data classification and mobile crowd sensing management. It gives all possible methods for meeting different kinds of security challenges and vulnerabilities.

In the work of Sarjerao and Prakasarao (2018) and Shah and Mishra (2016), helps to monitor the quality of various parameters such as $\mathrm{CO}, \mathrm{CO} 2$, temperature, humidity, and air pressure. IoT plays a major role in this model. IoT is integrated with cloud computing for better management of different data sources, and it is designed with low power and low-cost arm based minicomputer Raspberry pi. The main aim of this project is to identify pollutants in water with the help of IoT. Ultraviolent light sensor is used along with a 2 in one temperature and $\mathrm{PH}$ sensor. With the help of these sensors the purity of water, surrounding temperature, turbidity as well as acid and base levels of the water can be monitored. This data is transferred through cloud (Jamil et al., 2015; Guanochanga et al., 2018).

In this model a circuit is designed in such a way that it always keeps an eye on the amount of solid and gaseous wastes emitted by vehicles, industries, and others etc., Sensors are used to determine the level of co and co2 emitted and to determine humidity levels. Normal and abnormal values are recorded and transmitted to the user through IoT (Saha et al., 2017).

In the study of Huang et al. (2018) a wireless gas monitoring mechanism is designed which can detect the 3 fixed toxic gases i.e., $\mathrm{CO}, \mathrm{CO} 2$ and $\mathrm{CH} 2 \mathrm{O}$. The detected data can be monitored by the user with the help of an android app. Through this app the levels of these gases are known and when they exceeded a particular limit the user gets notified and the required precautionary measures were also sending to the user. Here instead of Wi-Fi, Bluetooth module is used which consumes low power. Also, the power consumption data 
is also transferred to the user to know the amount of power consumed along the sensor adjustment values.

In the works of Yang et al. (2017) and Benammar et al. (2018) provide an effective algorithm in which the pollution monitor is done by taking two different areas are considered i.e., a 2-D space like footpath and a 3-D space like a room inside a building. Sensors are used to determine the level of toxic impurities, when hardware is implemented and based on results the precautionary measures was taken. This is highly accurate method and consumes low power to a great extent, but only drawback is that the design of algorithm is a time taking process.

Marques, Ferreira, and Pitarma (2019) and Ahmed, Banu, and Paul (2017) discuss about SHE management system. SHE means Safety, Health and Environment management system. SHE is designed based on ZigBee wireless sensor network. It mainly focuses on Industrial sites. It contains a sensing network, router network and a monitoring network. It can measure various parameters and gas concentration. Any gas exceeding a particular limit this system warns the user and inform to take immediate precautionary measures.

\section{MATERIALS AND METHODS}

\subsection{WIRELESS INSPECTION AND NOTIFICATION (WINS) THROUGH IOT}

This project proposes Wireless Inspection and Notification System (WINS) through the concept of internet of things (IoT) as shown in Figure 1. By implementing the system, it is possible to identify the harmful gases that present in the environment. In this system, it uses GPRS based technology as a low cost and smart wireless communication method is adopted to collect and transmit the information about the harmful gases. WINS systems monitor the pollution and update it to web server so that the user can monitor anywhere through internet. The collected information will be stored for future purposes. 


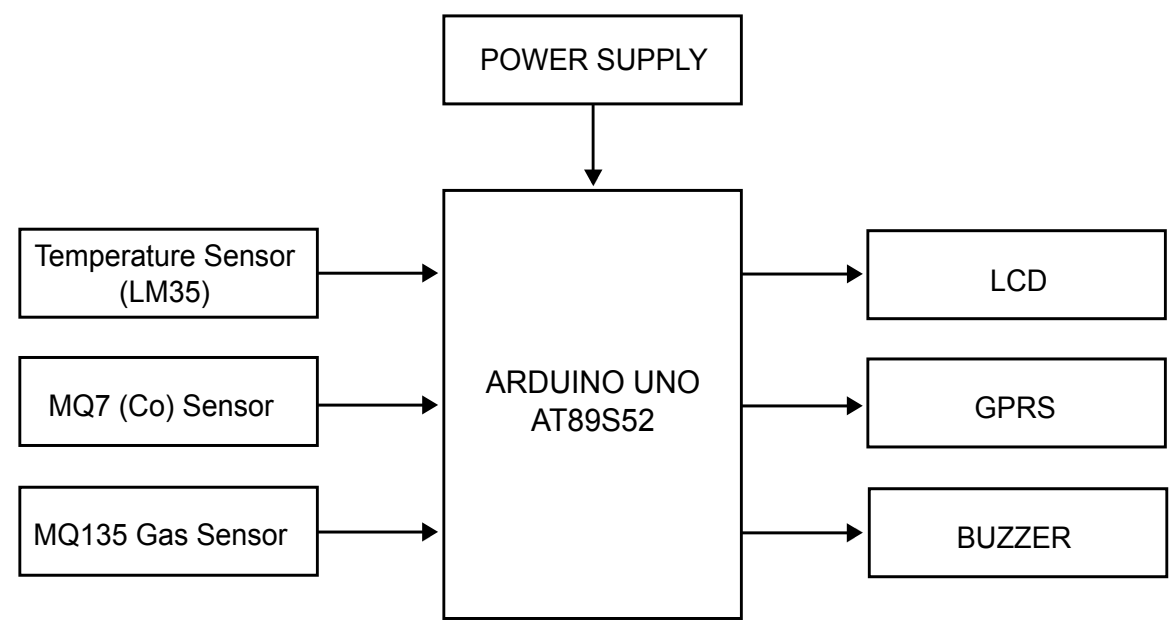

Figure 1. Block Diagram.

Source: own elaboration.

The main concept of this system is to identify the gas with the use of MQ135 and MQ6 gas sensors. The MQ135 sensor can sense NH3, NOx, Alcohol, Benzene, Smoke, and CO2. When the components are connected in an Arduino, it will sense all gases and it provides the gaseous level in PPM (Parts per Million). The output of the gas level is converted with respect to PPM, uses a library function of MQ135 and MQ7 gas sensor. The air quality safe level is 350PPM. If the value of air quality level exceeds 1000PPM, it leads to sleepiness, headache, and stuffy air. If the value increases beyond 2000PPM it leads to increased heart rate and other diseases. If the value is less than 1000PPM, then the LCD and Web page will display "Fresh air". When the value will be more than 1000PPM, then Buzzer will give beep sound and the LCD display shown the air level like "Poor Air, and the web page screen like Open Windows". When the gas level is increases above 2000PPM the buzzer will keep giving beep sound and it gives alert message in smart phone through GPS Module. The LCD and Web page will display "Harmful Air, go to Fresh Air".

\section{Temperature sensor (LM35):}

The LM35 series are precision integrated circuit. This sensor is used to detect the amount of temperature that present in the surroundings. It provides the output in centigrade, and it displays the output on LCD. 


\section{MQ7(CO):}

It is a sensor which is used to detect the harmful gases like $\mathrm{CO}$ and $\mathrm{CO} 2$ and provides the output values on LCD.

\section{MQ135 Gas sensor:}

The MQ135 sensor can sense NH3, Alcohol, Benzene, Smoke, CO2. When these components are connected to Arduino then it will sense all gases and it provides the gaseous level in PPM.

\section{Arduino Uno At89s52:}

Arduino board is used to boot the program from ROM memory, and it will wait for the sensor data. And it converts an analog data to the digital using ADC converter. If the sensor data is beyond the critical value alert a message will be send to the IOT web page.

\section{LGD:}

It is electrically modulated optical device that uses the light modulating properties of liquid crystal. It is used to display the threshold values of harmful gases like co2 and co. it also indicates gases values in PPM.

\section{GPRS:}

GPRS provides data rates of $56-144 \mathrm{~K}$ bits/second and has a moderate speed data transform. This system is an integrated part of GSM network switching sub system. This component is used for long distance communication. With the use of this component the user can be able to monitor the gases values from longer distances with the use of web page.

\section{BUZZER:}

Buzzer is an audio signaling device. It is used to provide the alert message like buzzing or beeping sound when the harmful gases are emitted in the atmosphere. 


\section{RESULTS}

Hardware implementation of an air pollution monitoring system output as shown in Figure 2. The above figure shows the result that it contains the level of $\mathrm{CO} 2$ and shows the temperature value. Whenever the sensors used in the system, it is used to detect the gases that present in the atmosphere. If there is a gas, proposed method gives an alarm sound with the help of buzzer. This alarm sound will be considered as an alert message to take the preventive measures.

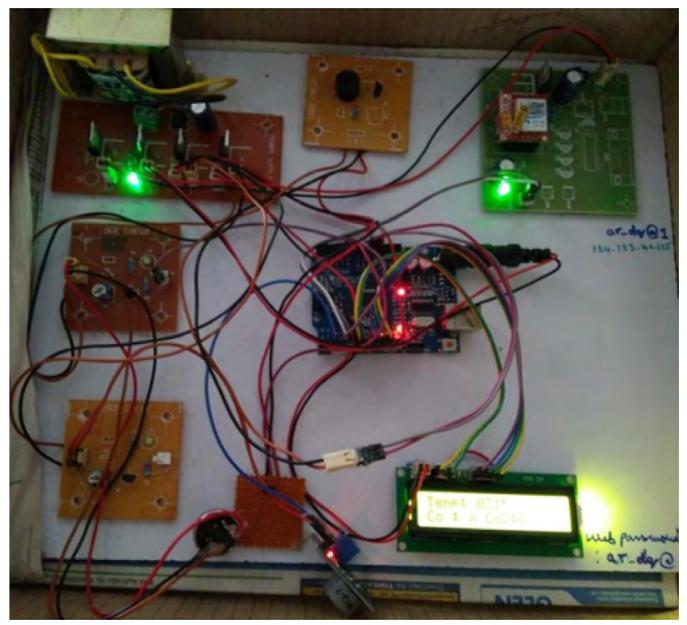

Figure 2. Output of Air Pollution Monitoring System.

Source: own elaboration.
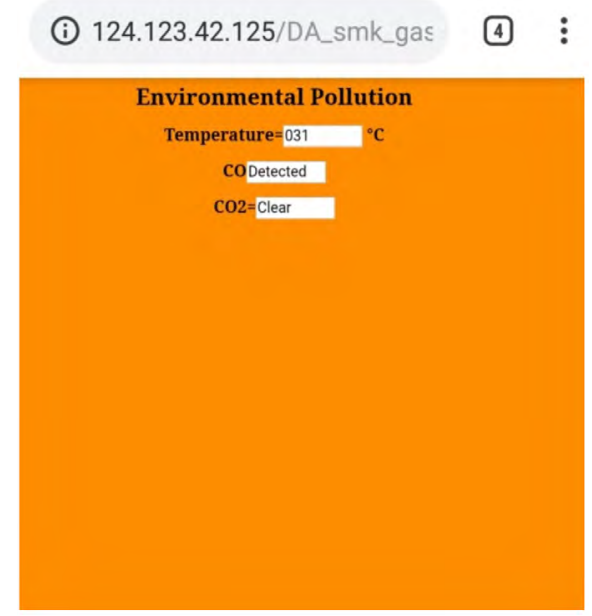

Figure 3. Result of webpage.

Source: own elaboration. 
In this project GPRS module is used. Figure 3. shows that the temperature value and the status of the gas has been displayed using web page.

\section{CONCLUSIONS}

This work proposed Wireless Inspection and Notification (Wins) through IOT. It is used to monitor the air pollution using Arduino UNO board and GPRS module using IoT technology. This technology is used to monitor the quality of an air. Here MQ7 and MQ135 sensors used to sense the various types of dangerous gases. GPRS module is used to monitor the gas concentration from longer distances, and it connects entire process to internet. LCD (Liquid Crystal Display) is used to display the gaseous values. By using of buzzer, the user can get the alert message. This alert message is used to take the preventive measures by the user. This proposed system will be useful for society.

\section{ACKNOWLEDGEMENT}

We would like to thank International Research Center of Kalasalingam Academy of Research and Education for providing financial assistance under the scheme of University Research Fellowship(URF) and we also thank the Department of Electronics and Communication Engineering of Kalasalingam Academy of Research and Education, India for permitting to use the computational facilities available in Signal Processing and VLSI Design which was setup with the support of the Department of Science and Technology (DST).

\section{REFERENCES}

Ahmed, M. M., Banu, S., \& Paul, B. (2017). Real-time air quality monitoring system for Bangladesh's perspective based on Internet of Things. In 2017 3rd International Conference on Electrical Information and Communication Technology (EICT) (pp. 1-5). IEEE. https:// www.semanticscholar.org/paper/Real-time-air-quality-monitoring-systemfor-based-Ahmed-Banu/520860de7d1f77d12480151d198945fe25bb678d

Benammar, M., Abdaoui, A., Ahmad, S. H., Touati, F., \& Kadri, A. (2018). A modular IoT platform for real-time indoor air quality monitoring. Sensors, $18(2), 581$. https://doi.org/10.3390/s18020581 


\section{Cataliotti, A., Gipriani, G., Cosentino, V., Di Cara, D., Di Dio, V., Guaiana, S.,} Panzavecchia, N., \& Tinè, G. (2014). A prototypal architecture of a IEEE 21451 network for smart grid applications based on power line communications. IEEE Sensors fournal, 15(5), 2460-2467. https://ieeexplore.ieee.org/document/6849478

Devahema, P. V., Vamsi, S. S., Garg, A., Anand, A., \& Gupta, D. R. (2018). IoT Based Air Pollution Monitoring System. Fournal of Network Communications and Emerging Technologies (fNCET), 8(4), 100-103. https://www.jncet.org/Manuscripts/Volume-8/ Issue-4/Vol-8-issue-4-M-23.pdf

Gu, K., Qiao, J., \& Lin, W. (2018). Recurrent air quality predictor based on meteorologyand pollution-related factors. IEEE Transactions on Industrial Informatics, 14(9), 39463955. https://ieeexplore.ieee.org/document/8259327

Guanochanga, B., Gachipuendo, R., Fuertes, W., Salvador, S., Benítez, D. S., Toulkeridis, T., Torres, J., Tapia, F., \& Meneses, F. (2018). Real-time air pollution monitoring systems using wireless sensor networks connected in a cloudcomputing, wrapped up web services. In Proceedings of the future technologies conference (pp. 171-184). Springer, Cham. https://www.semanticscholar.org/paper/RealTime-Air-Pollution-Monitoring-Systems-Using-in-Guanochanga-Cachipuendo / Ofa 7f310ef4ace2dle7e6470bdd3c64983fe10a8

Huang, G. M., Liu, Y. J., Hsieh, Y. J., Lai, W. L., Juan, G. Y., Chen, S. Y., Yang, G. C., \& Wu, C. M. (2018). A multi-gas sensing system for air quality monitoring. In 2018 IEEE International Conference on Applied System Invention (ICASI) (pp. 834-837). IEEE. https://ieeexplore.ieee.org/document/8394393

Huang, C. M., Liu, Y. J., Hsieh, Y. J., Lai, W. L., Juan, C. Y., Chen, S. Y., ... \& Wu, C. M. (2018). A multi-gas sensing system for air quality monitoring. In 2018 IEEE International Conference on Applied System Invention (ICASI) (pp. 834-837). IEEE.

Jamil, M. S., Jamil, M. A., Mazhar, A., Ikram, A., Ahmed, A., \& Munawar, U. (2015). Smart environment monitoring system by employing wireless sensor networks on vehicles for pollution free smart cities. Procedia Engineering, 107, 480-484. https:// doi.org/10.1016/j.proeng.2015.06.106 
Kumar, S., \& Jasuja, A. (2017). Air quality monitoring system based on IoT using Raspberry Pi. In 2017 International Conference on Computing, Communication and Automation (ICCCA) (pp. 1341-1346). IEEE. https://www.semanticscholar.org/paper/Airquality-monitoring-system-based-on-IoT-using-Pi-Kumar-Jasuja/78a0ea3f1 12ee0d dcd9baeb6cddeceffaal8157f

Maag, B., Zhou, Z., \& Thiele, L. (2018). A survey on sensor calibration in air pollution monitoring deployments. IEEE Internet of Things Fournal, 5(6), 4857-4870. https:// ieeexplore.ieee.org/abstract/document/8405565

Mansour, S., Nasser, N., Karim, L., \& Ali, A. (2014). Wireless sensor network-based air quality monitoring system. In 2014 International Conference on Computing, Networking and Communications (ICNC) (pp. 545-550). IEEE. https://www.semanticscholar.org/ paper/Wireless-Sensor-Network-based-air-quality-system-Mansour-Nasser/2c78e3 e28b85345a5f32alf1819bcae8e75dc99b

Marques, G., Ferreira, G. R., \& Pitarma, R. (2019). Indoor air quality assessment using a CO 2 monitoring system based on internet of things. Fournal of medical systems, 43(3), 1-10. https://doi.org/10.1007/s10916-019-1184-x

Parmar, G., Lakhani, S., \& Chattopadhyay, M. K. (2017). An IoT based low cost air pollution monitoring system. In 2017 International Conference on Recent Innovations in Signal processing and Embedded Systems (RISE) (pp. 524-528). IEEE. https://www. semanticscholar.org/paper/An-IoT-based-low-cost-air-pollution-monitoringParmar-Lakhani/172a48db2a15ce2b73ce62e9981 lefc067f20672

Phala, K. S. E., Kumar, A., \& Hancke, G. P. (2016). Air quality monitoring system based on ISO/IEC/IEEE 21451 standards. IEEE Sensors fournal, 16(12), 5037-5045. https://ieeexplore.ieee.org/document/7456204

Saha, H. N., Auddy, S., Chatterjee, A., Pal, S., Sarkar, S., Singh, R., Singh, A. K., Sharan, P., Banerjee, S., Sarkar, R., \& Maity, A. (2017). IoT solutions for smart cities. In 8th Annual Industrial Automation and Electromechanical Engineering Conference (IEMECON). https://ieeexplore.ieee.org/document/8079565 
Sarjerao, B. S., \& Prakasarao, A. (2018). A low cost smart pollution measurement system using rest api and esp32. In 2018 3rd International Conference for Convergence in Technology (I2CT) (pp. 1-5). IEEE. https://ieeexplore.ieee.org/document/8529500

Shah,J., \& Mishra, B. (2016). Io T enabled environmental monitoring system for smart cities. In 2016 internationalconferenceoninternet of things and applications (IOTA) (pp. 383-388).IEEE. https://www.semanticscholar.org/paper/IoT-enabled-environmental-monitoringsystem-for-Shah-Mishra/b4ff3a0490d5de57ecc8acb3ae951e49c8fcb50e

Xiaojun, G., Xianpeng, L., \& Peng, X. (2015). IOT-based air pollution monitoring and forecasting system. In 2015 international conference on computer and computational sciences (ICCCS) (pp. 257-260). IEEE. https://www.semanticscholar.org/paper/IOT-basedair-pollution-monitoring-and-forecasting-Xiaojun-Xianpeng/508b2d446d0864ee4 cefc01c0a008c5c99525lab

Yang, Y., Zheng, Z., Bian, K., Song, L., \& Han, Z. (2017). Real-time profiling of finegrained air quality index distribution using UAV sensing. IEEE Internet of Things fournal, 5(1), 186-198. https://ieeexplore.ieee.org/document/8119942 